\title{
EFEITO DO TAMANHO DE SEMENTES SOBRE A TOLERÂNCIA DO FEIJOEIRO AO S-METOLACHLOR, EM CONDIÇÕES DE BAIXA TEMPERATURA
}

\author{
Sérgio de Oliveira Procópio ${ }^{1}$, Antônio Alberto da Silva², José Barbosa dos Santos ${ }^{3}$, Eduardo Fontes Araújo², \\ José Ivo Ribeiro Júnior ${ }^{4}$ e Lino Roberto Ferreira ${ }^{2}$
}

'Engo. Agrônomo, Doutorando. UFV, Depto. de Fitotecnia. Av. PH Rolfs s/n. Viçosa, MG 36571-000 procopio@alunos.ufv.br

${ }^{2}$ Professor. UFV, Depto. de Fitotecnia.

${ }^{3}$ Acadêmico. UFV, Depto. de Fitotecnia.

${ }^{4}$ Professor. UFV, Depto. de Informática.

\section{RESUMO}

O objetivo do trabalho foi avaliar o efeito do herbicida s-metolachlor sobre plantas de feijão (Phaseolus vulgaris L.), oriundas de sementes com diferentes tamanhos, cultivadas em condições de baixa temperatura. O experimento foi conduzido em câmara de crescimento com fotoperíodo de $12 \mathrm{~h}$, temperatura média de $16 / 13 \pm 3^{\circ} \mathrm{C}$ (dia/noite) e $300 \mu$ mol de radiação fotossinteticamente ativa (RFA) $/ \mathrm{m}^{2} \mathrm{~s}$, tendo sido utilizado o cultivar Pérola, pertencente ao grupo Carioca. Os tratamentos foram formados por todas as combinações de três tamanhos de sementes (peneiras 14, 18 e 21) e de quatro doses de smetolachlor $(0,00,0,96,2,88$ e $4,80 \mathrm{~kg} / \mathrm{ha})$, totalizando 12 tratamentos. O delineamento experimental utilizado foi o inteiramente casualizado, em esquema fatorial $(3 \times 4)$ com quatro repetições. O herbicida foi aplicado em pré-emergência, sendo realizadas as seguintes avaliações: 1) tempo gasto (dias) até a emergência de $75 \%$ das plântulas; 2) estande final; 3) percentagem de toxicidade; 4) altura das plantas; 5) biomassa seca da parte aérea; e 6) biomassa seca das raízes. Observouse relação inversa entre o tamanho das sementes e velocidade de emergência das plântulas de feijão. O tamanho das sementes e as doses do s-metolachlor aplicadas não interferiram no número de plantas emergidas. $\mathrm{O}$ aumento nas doses do s-metolachlor reduziu o acúmulo de biomassa seca da parte aérea das plantas de feijão em maior intensidade do que a das raízes, para todos os tamanhos de sementes. Plantas de feijão provenientes de sementes maiores (peneira 21) apresentaram maior toxicidade visual $(71 \%)$ ao s-metolachlor na maior dose aplicada, não apresentando, contudo, redução na biomassa.

Palavras-chave: cloroacetamidas, herbicida, Phaseolus vulgaris.

\section{ABSTRACT \\ Effect of seed size on dry bean tolerance to s-metolachlor under low temperature conditions}

The objective of the work was evaluate the potential phytotoxic effects of s-metolachlor herbicide on different sizes of seeds of a single bean variety cultivar belonging to a same lot, in low temperature conditions. The experiment was carried out in a growth chamber with 12 hours photofase, $16 / 13 \pm 3^{\circ} \mathrm{C}$ (day/night) temperature (until plant emergence) and $300 \mu \mathrm{mol}$ of photosynthetically active radiation (PAR) $/ \mathrm{m}^{2} \mathrm{~s}$. The cultivar used was Pérola, belonging to the Carioca group. The treatments included the combination of three seed sizes (sieves 14,18 and 21$)$ and four s-metolachlor doses $(0.00,0.96,2.88$ and 4.80 $\mathrm{kg} / \mathrm{ha}$ ), totalling 12 treatments. The herbicide was applied preemergence, the following evaluations being carried out: 1) time (days) until the emergence of $75 \%$ of the seedlings; 2) number of emerged plant in the crop; 3 ) visual toxicity; 4) final plant height; 5) final dry matter of the aerial part; and 6) final dry matter of the roots. The larger the seed size the most retarded was the emergence of the bean plant. The seed sizes together with the s-metolachlor levels did not interfere in the number of emerged plants. The increase in the s-metolachlor doses caused higher reduction in the dry matter of the aerial part of the 
Sérgio de Oliveira Procópio et al.

bean plants than the roots, for all the seeds sizes. Plants from larger seeds presented high herbicide toxicity levels, reaching $71 \%$ of symptoms at the highest s-metolachlor dose $(4,80 \mathrm{~kg} / \mathrm{ha}$ ) and largest seed size (sieve 21$)$, though no dry matter reduction was observed.

Key words: chloroacetamides, herbicide, Phaseolus vulgaris.

\section{INTRODUÇÃO}

No Brasil, a cultura que apresenta o maior consumo do herbicida metolachlor é o milho. Todavia, com o aumento das áreas de cultivo do feijão no inverno, esta cultura passou também a ser um importante mercado desse herbicida. Problemas de toxicidade de metolachlor às plantas de feijão têm ocorrido esporadicamente. Vários trabalhos indicam que sob temperaturas baixas estes problemas podem ser agravados. Para Boldt \& Barret (1989), a cultura do milho normalmente é tolerante ao metolachlor, mas injúrias na cultura causadas por aplicações em pré-emergência têm sido observadas quando ocorrem temperatura baixa e alta umidade do solo antes da emergência da cultura. Putnam \& Rice Junior (1979), avaliando a toxicidade do alachlor a plantas de feijão (Phaseolus vulgaris L.), em duas faixas de temperatura (16-21 e 27-32 $\left.{ }^{\circ} \mathrm{C}\right)$, concluíram que na temperatura mais baixa a toxicidade observada nas plântulas de feijão foi 2,5 vezes maior que na temperatura mais elevada. De acordo com Peter \& Weber (1985), os herbicidas alachlor e metolachlor são sememlhantes quanto a seletividade às culturas e ao espectro de ação sobre as plantas daninhas. Viger et al. (1991), estudando os efeitos da interação entre níveis de água no solo versus temperatura, sobre a tolerância do milho ao metolachlor, observaram correlação direta entre nível de injúria e o aumento na dose do herbicida, porém, a toxicidade foi maior nas plantas crescidas em vasos mantidos com maior umidade inicial do substrato e submetidos a temperatura menor. Resultados semelhantes foram observados por Jordan \& Harvey (1978), que verificaram que a tolerância de plantas de milho e ervilha ao alachlor diminuiu com o aumento na umidade do solo e com o decréscimo na temperatura.

Os sintomas mais comuns provocados pelo metolachlor nas plantas são: enrugamento foliar, folhas em "formato de concha" e folhas retorcidas. Em plantas de soja é típico as folhas ficarem em "forma de coração" (Colvin \& Stall, 1998). Fuerst \& Gronwald (1986) relatam que em gramíneas intoxicadas pelo metolachlor, as folhas podem não se desenvolver do coleóptilo e, quando se desenvolvem, freqüentemente não se desenrolam completamente. Em latifoliadas, a emergência é retardada e as folhas podem ficar enrugadas ou em "forma de concha", além da redução no crescimento da parte aérea e de raízes em ambos os grupos de plantas.

A seletividade ao metolachlor pode estar ligada a vários fatores como: o solo, o clima, o manejo da irrigação e a dose do produto, entre outros. Características relacionadas às sementes das culturas, como o tamanho, também podem influenciar na tolerância do metolachlor, todavia são pouco estu- dadas. Klimont (1996), testando o efeito dos herbicidas metribuzin e linuron sobre sementes de três cultivares de soja, observaram decréscimos na germinação e aumento da percentagem de plântulas anormais, quando se utilizou doses elevadas desses herbicidas. Andersen (1970) verificou diminuição na biomassa seca da parte aérea de vários cultivares de soja quando as sementes foram semeadas em solo com atrazine, e que esta redução aumentava à medida que o tamanho das sementes dos cultivares diminuía. Esse autor concluiu que $80 \%$ da redução ocorrida era devida ao tamanho das sementes e que cultivares de soja que apresentam sementes grandes são mais tolerantes ao atrazine.

Este trabalho teve como objetivo avaliar o efeito do smetolachlor, sobre a emergência e o desenvolvimento inicial do feijoeiro, cultivar Pérola, oriundo de sementes com diferentes tamanhos e cultivados em condições de baixa temperatura.

\section{MATERIAL E MÉTODOS}

O experimento foi conduzido em câmara de crescimento, regulada para fotoperíodo de 12 horas, temperatura média de $16 / 13 \pm 3^{\circ} \mathrm{C}$ (dia/noite) e $300 \mu$ mol de radiação fotossinteticamente ativa (RFA) $/ \mathrm{m}^{2} \mathrm{~s}$, utilizando-se o cultivar de feijão (Phaseolus vulgaris L.) Pérola, pertencente ao grupo Carioca. Os tratamentos foram compostos pelas combinações de três grupos de tamanhos de sementes, classificadas em peneiras de crivo oblongo [sementes retidas na peneira de largura 14/64" (peneira 14), na peneira 18/64" (peneira 18) e na peneira 21/64"'(peneira 21)] e de quatro doses do herbicida s-metolachlor $(0,00,0,96,2,88$ e $4,80 \mathrm{~kg} / \mathrm{ha})$, totalizando 12 tratamentos. O delineamento experimental utilizado foi o inteiramente casualizado, em esquema fatorial (3x4) com quatro repetições.

Após a separação das sementes, estas foram semeadas em caixas gerbox $(10 \times 10 \times 3 \mathrm{~cm})$ preenchidas com solo homogeneizado, cujas características física e química encontram-se na Tabela 1.

Em cada gerbox foram semeadas três sementes de feijão, na profundidade de $1,5 \mathrm{~cm}$, realizando-se em seguida a aplicação do s-metolachlor no topo dos recipientes, utilizando-se um pulverizador de precisão, com volume de aplicação de 200 1/ha. Após a semeadura e aplicação do s-metolachlor, manteve-se o substrato em todas as parcelas com mesmo teor de água (próximo a capacidade de campo) até a colheita do experimento [40 dias após a semeadura (DAS)]. 
Efeito do tamanho de sementes sobre a tolerância do feijoeiro ao s-metolachlor

Tabela 1. Características físicas e químicas do solo utilizado. Análises realizadas nos Laboratórios de Análises Físicas e Químicas de Solo do Departamento de Solos da UFV, segundo a metodologia da EMBRAPA (1997).

\begin{tabular}{|c|c|c|c|c|c|c|c|c|}
\hline & \multicolumn{4}{|c|}{ Análise granulométrica } & \multicolumn{4}{|c|}{ Análise química } \\
\hline Solo utilizado & Argila & Silte & Areia fina & Areia grossa & $\mathrm{t}$ & $\mathrm{T}$ & MO & $\begin{array}{c}\mathrm{pH} \\
\mathrm{H}_{2} \mathrm{O}\end{array}$ \\
\hline$-\ldots---\ldots$ & ----- & $\ldots$ & $\mathrm{dag} / \mathrm{kg}$ & $\ldots \ldots$ & $--\mathrm{cm}$ & $\mathrm{m}^{3}$ & - dag/kg_ & - - - - \\
\hline Areia Quartzosa & 16 & 29 & 20 & 35 & 1,18 & 2,58 & 1,90 & 5,90 \\
\hline
\end{tabular}

Para propiciar um bom desenvolvimento das plantas, foi realizada a aplicação de solução nutritiva comercial em igual volume para todos os tratamentos, uma vez por semana.

Foram realizadas as seguintes avaliações: tempo em dias para emergência de $75 \%$ das plântulas (velocidade de emergência); toxicidade visual aos 40 DAS (utilizando-se a escala do IAPAR, citada por Pereira \& Bazoni, 1995), onde $0 \%$ significa nenhuma injúria e $100 \%$ morte da planta; número de plantas emergidas aos 40 DAS; altura das plantas aos 40 DAS; biomassa seca das raízes e da parte aérea aos 40 DAS.

Todas as variáveis que atenderam às pressuposições de normalidade e homogeneidade das variâncias, por meio dos testes de Lilliefors e de Cochran, respectivamente, foram submetidas à análise de variância para a verificação de significância dos dois fatores estudados e da interação entre eles pelo teste F. A comparação entre tamanhos de sementes foi feita por meio do teste de Tukey, e entre doses do smetolachlor por análise de regressão. Os dados de velocidade de emergência das plântulas e de toxicidade visual, foram analisadas utilizando-se estatística descritiva, por não terem atendidos às pressuposições da análise de variância; todavia, para esta última avaliação foi realizada análise de regressão, em cada tamanho de sementes, a fim de se avaliar as doses intermediárias no respectivo intervalo. Para a análise de variância com o teste F e para o teste de Tukey, foi adotado o nível de significância igual a 5\%. Para a análise de regressão, foram adotados os níveis de $1 \%$ ou de $5 \%$ de significância.

\section{RESULTADOS E DISCUSSÃO}

a) Velocidade de emergência das plântulas

Não se observaram diferenças entre os efeitos do smetolachlor no intervalo das doses avaliadas para todos os tamanhos de sementes, sobre a velocidade de emergência das plântulas de feijão (Tabela 2). Resultados semelhantes foram observados por Amaral \& Santos (1983) para os herbicidas butachlor, oxadiazon e pendimethalin, os quais não afetaram a velocidade de emergência de plântulas de vários cultivares de arroz.

Por outro lado, concordando com vários autores (Burris et al., 1971; Edwards Junior \& Hartwig, 1971; Costa et al., 1973), observou-se neste trabalho (Tabela 2) uma tendência a haver uma relação inversa entre o tamanho das sementes e a velocidade de emergência. Também, Vechi (1970) observou em Vigna spp. a emergência mais rápida de plântulas provenientes de sementes "pequenas", todavia com desenvolvimento inicial menos vigoroso. Contudo, Oliveira \& Sader (1984), estudando o caupi, observaram correlação positiva entre o peso de 100 sementes, germinação, índice de velocidade de emergência em laboratório e biomassa seca das plântulas. Hsu et al. (1983) observaram relação inversa entre tamanho de semente e velocidade de absorção de água e atribuem este fato a maior área de contato das sementes de menor tamanho, por unidade de massa. Todavia, em pesquisa desenvolvida por Aguiar et al. (1979), observou-se que a capacidade de germinação de sementes de Eucalyptus grandis e E. urophylla, separadas em vários tamanhos não foi afetada, porém, as sementes "médias" e "grandes" germinaram mais rapidamente do que as "pequenas". Para Cottingham \& Hatzios (1992), em condições de campo, lento crescimento de plântulas de milho pode aumentar a sua sensibilidade ao metolachlor, por prolongar o tempo de contato entre o coleóptilo e o solo tratado com o herbicida.

b) Número de plântulas emergidas

Não se observaram efeitos significativos $(\mathrm{P}>0,05)$ para tamanho de sementes e para doses do s-metolachlor sobre o estande final da cultura aos 40 dias após a semeadura (Tabe-

Tabela 2. Efeito do tamanho de sementes de feijão (cv. Pérola) sobre o tempo médio necessário para a emergência de $75 \%$ das plântulas, em condições de baixa temperatura $\left[16 / 13 \pm 3^{\circ} \mathrm{C}(\right.$ dia/noite $\left.)\right]$.

\begin{tabular}{cc}
\hline $\begin{array}{c}\text { Tamanho das sementes } \\
\text { (peneiras de crivo oblongo) }\end{array}$ & $\begin{array}{c}\text { Tempo médio para emergir } \\
\text { 75\% das plântulas (dias) }\end{array}$ \\
\hline 14 & 14 \\
18 & 16 \\
21 & 17 \\
\hline
\end{tabular}


la 3). Estes resultados concordam com o encontrado por Singh et al. (1972) e Johnson \& Luedders (1974), os quais, trabalhando com cultivares de soja com diferentes tamanhos de sementes, concluíram que esta característica não influiu sobre a emergência das plântulas. Também Beveridge \& Wilsie (1959) registram que a resposta na emergência em plântulas de alfafa não se correlacionou com o tamanho das sementes. Entretanto, Silva \& Marcos Filho (1979) observaram superioridade em relação à germinação e o vigor em sementes de milho retidas na peneira 24 em relação às retidas na peneira 20.

\section{c) Sintomas de toxicidade}

Nos tratamentos onde se aplicou o s-metolachlor, as plantas oriundas das sementes maiores (peneira 21) apresentaram maior nível de danos, chegando ao valor de $71,25 \%$ para a maior dose aplicada. Este índice de toxicidade é considerado pesado, não recuperável e podendo causar redução no estande (Pereira \& Bazoni, 1995). Todavia, a toxicidade

Tabela 3. Efeito de doses de s-metolachlor ( $\mathrm{kg} / \mathrm{ha})$ e tamanhos de sementes de feijão (cv. Pérola), submetidas à baixa temperatura entre a semeadura e a emergência $\left[16 / 13 \pm 3^{\circ} \mathrm{C}\right.$ (dia/noite) $]$, sobre o número de plantas emergidas, aos 40 dias após a semeadura.

\begin{tabular}{cccccc}
\hline & \multicolumn{4}{c}{ Doses de s-metolachlor (kg/ha) } & \\
\cline { 2 - 4 } $\begin{array}{c}\text { Peneiras } \\
\text { de crivo } \\
\text { oblongo }\end{array}$ & $\mathbf{0}$ & $\mathbf{0 , 9 6}$ & $\mathbf{2 , 8 8}$ & $\mathbf{4 , 8 0}$ & \multirow{2}{*}{$\begin{array}{c}\text { Número de plantas emeros de } \\
\text { regressão }\end{array}$} \\
\hline 14 & 2,75 a & 2,50 a & 2,25 a & 2,25 a & $\hat{Y}=2,4375$ \\
18 & 2,50 a & 3,00 a & 3,00 a & 2,75 a & $\hat{Y}=2,8125$ \\
21 & 2,75 a & 3,00 a & 3,00 a & 2,75 a & $\hat{Y}=2,8750$ \\
\hline
\end{tabular}

Médias seguidas por uma mesma letra, na coluna, não diferem entre si a $5 \%$ de probabilidade pelo teste de Tukey.

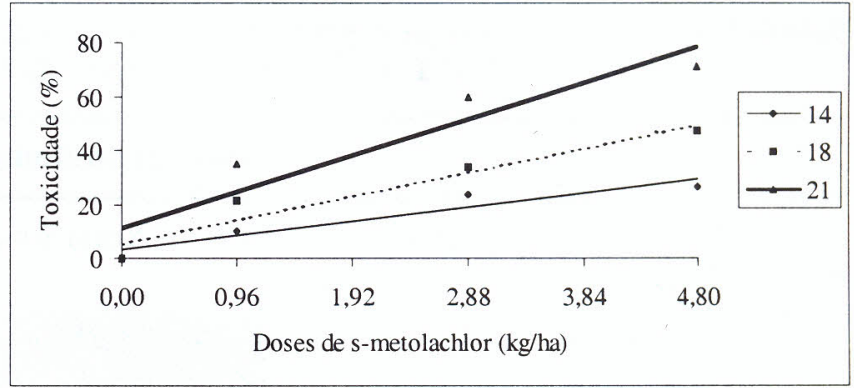

Figura 1. Efeito das doses de s-metolachlor (kg/ha) sobre a intensidade dos sintomas de toxicidade em plantas de feijão (cv. Pérola), provenientes de sementes de diferentes tamanhos (peneiras 14, 18 e 21), aos 40 dias após a semeadura.

do s-metolachlor, na mesma dose, observada em plântulas oriundas de sementes da peneira 14 (26,25\%), foi aproximadamente três vezes menor em relação à toxicidade ocorrida na peneira 21 , sendo esta considerada aceitável, recuperável e sem prováveis prejuízos futuros (Pereira \& Bazoni, 1995). Na dose do s-metolachlor recomendada pelo fabricante $(0,96$ $\mathrm{kg} / \mathrm{ha}$ ), a toxicidade máxima foi de 35\% (Tabela 4), nível este, segundo Pereira \& Bazoni (1995), já acima do aceitável (30\%).

Para todos os tamanhos de sementes, os sintomas de toxicidade do s-metolachlor se agravaram à medida em que se aumentou a dose do herbicida (Figura 1). Entretanto, percebe-se que esse aumento foi mais acentuado nas plantas provenientes de sementes da peneira 21 . Tal fato pode ser atribuído à maior área de absorção de solução do solo presente nas sementes de grandes dimensões, propiciando maior absorção do herbicida, e refletindo assim em altos níveis de dano no estádio inicial de crescimento das plantas. Também Fuentes et al. (1984) concluíram que os cultivares de feijão mais tolerantes ao alachlor apresentavam sementes pretas e peso menor (Negrito 897 e Costa Rica); os mais sensíveis apresentavam sementes "mulatinhas e pardas" e peso maior (Ricobaio 1014 e Rico Pardo 896). Estes autores afirmam

Tabela 4. Efeito de doses de s-metolachlor ( $\mathrm{kg} / \mathrm{ha})$ e tamanhos de sementes de feijão (cv. Pérola), submetidas à baixa temperatura entre a semeadura e a emergência $\left[16 / 13 \pm 3^{\circ} \mathrm{C}\right.$ (dia/noite)], sobre a intensidade dos sintomas visuais de toxicidade do herbicida às plantas aos 40 dias após a semeadura.

\begin{tabular}{|c|c|c|c|c|c|}
\hline \multirow{3}{*}{$\begin{array}{l}\text { Peneiras } \\
\text { de crivo } \\
\text { oblongo }\end{array}$} & \multicolumn{4}{|c|}{ Doses de s-metolachlor (kg/ha) } & \multirow{3}{*}{$\begin{array}{l}\text { Equações de } \\
\text { regressão }\end{array}$} \\
\hline & $\mathbf{0}$ & 0,96 & 2,88 & 4,80 & \\
\hline & \multicolumn{4}{|c|}{ Sintomas de toxicidade nas plantas (\%) } & \\
\hline 14 & 0,00 & 10,00 & 23,75 & 26,25 & $\begin{array}{c}\hat{\mathrm{Y}}=3,17797+5,47316^{* *} \mathrm{D} \\
\left(\mathrm{R}^{2}=0,90\right)\end{array}$ \\
\hline 18 & 0,00 & 21,25 & 33,75 & 47,50 & $\begin{array}{c}\hat{\mathrm{Y}}=5,88983+9,13665^{* *} \mathrm{D} \\
\left(\mathrm{R}^{2}=0,93\right)\end{array}$ \\
\hline 21 & 0,00 & 35,00 & 60,00 & 71,25 & $\begin{array}{c}\hat{\mathrm{Y}}=11,4831+13,9257 * * \mathrm{D} \\
\left(\mathrm{R}^{2}=0,88\right)\end{array}$ \\
\hline
\end{tabular}


Efeito do tamanho de sementes sobre a tolerância do feijoeiro ao s-metolachlor

que as sementes de cores apresentam tegumento com maior espessura que as brancas, existindo portanto, uma relação entre o peso da semente e a quantidade de herbicida absorvido, ou seja, sementes pretas e leves apresentariam maior impermeabilidade à entrada do herbicida, originando plântulas mais vigorosas e com maior capacidade de metabolizar o alachlor. Todavia, outros autores encontraram resultados discrepantes. De acordo com Cargill \& Santelmann (1971), trifluralin causou maior nível de danos e redução da matéria seca em raízes de plântulas de amendoim originadas de sementes menores em relação às sementes "médias" e "grandes".

\section{d) Altura de plantas}

Nos tratamentos sem herbicida, as sementes oriundas das peneiras 18 e 21 deram origem a plantas com maior altura (Tabela 5). Resultados semelhantes foram encontrados por Burris et al. (1973) que, trabalhando com quatro tamanhos de sementes em quatro cultivares de soja, observaram que as sementes dos três maiores tamanhos apresentaram maior percentagem de emergência, e que as plântulas originadas destas apresentaram maior área foliar e maior altura. Também Figueiredo \& Vieira (1970) constataram que sementes "pequenas" dos cultivares Rico 23 e Manteigão Fosco originaram plantas que apresentaram menor altura. Silva (1979) afirma que populações oriundas de sementes "pequenas", geralmente, são constituídas de plantas de menor altura, até 20 a 30 dias após a semeadura. Resultado semelhante foi observado por Gillioli (1979), trabalhando com quatro cultivares de soja divididos em cinco tamanhos. Este autor observou que as diferenças na emergência, no grau de sobrevivência de plantas e no rendimento não foram significativas, porém na fase inicial de desenvolvimento observou estreita relação entre a altura de plantas (velocidade de crescimento) e o tamanho das sementes. Todavia, Cazetta et al. (1995) verificaram que o tamanho das sementes de feijão apresenta pouco efeito sobre a germinação e altura das plântulas; a biomassa seca das plântulas, cinco dias após a emergência, foi positi-

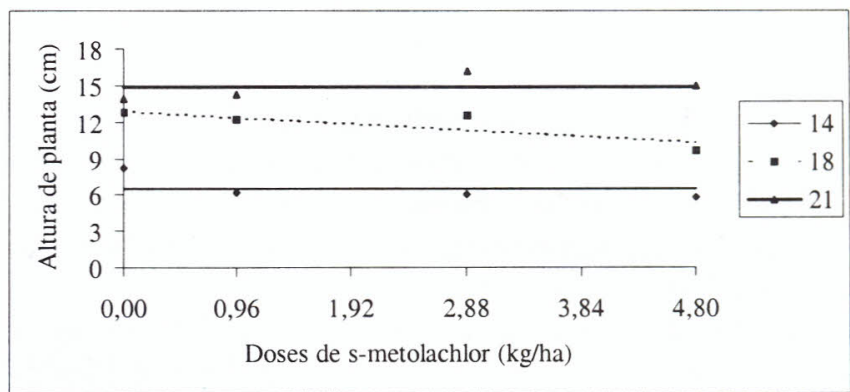

Figura 2. Efeito das doses de s-metolachlor ( $\mathrm{kg} / \mathrm{ha}$ ) sobre a altura de plantas de feijão (cv. Pérola), provenientes de sementes de diferentes tamanhos (peneiras 14,18 e 21), aos 40 dias após a semeadura.

vamente correlacionada com essa característica. Também observaram que o vigor era menor nas sementes "pequenas".

A presença do s-metolachlor parece ter acentuado as diferenças entre as alturas das plantas provindas das três peneiras. Com a atuação do herbicida, percebe-se superioridade na altura das plantas provenientes da peneira 21 em relação a 18 (Tabela 5). Como o s-metolachlor atua inibindo o crescimento de plântulas, reduzindo a síntese de vários compostos orgânicos fundamentais ao desenvolvimento, as plantas oriundas de sementes com altos níveis reservas, podem ser menos suscetíveis a ação desse herbicida em relação à elongação e ao acúmulo de biomassa seca.

$\mathrm{O}$ aumento nas doses do s-metolachlor induziu a inibição da altura de plantas originárias somente de sementes de tamanho médio (peneira 18) (Figura 2). Todavia, este decréscimo foi relativamente baixo $(0,5 \mathrm{~cm}$ para cada aumento de $1 \mathrm{~kg} /$ ha do s-metolachlor). Resultados semelhantes do metolachlor afetando a altura de plantas foi observado por Rowe et al. (1990), os quais trabalhando com 200 híbridos comerciais de milho, encontraram reduções na altura das plântulas tratadas variando de 26,0 a $73,0 \%$. Estes autores justificam tais resultados afirmando haver diferenças entre os híbridos quanto à quantidade absorvida e à habilidade de metabolização interna do herbicida.

Tabela 5. Efeito de doses de s-metolachlor (kg/ha) e tamanhos de sementes de feijão (cv. Pérola), submetidas à baixa temperatura entre a semeadura e a emergência $\left[16 / 13 \pm 3^{\circ} \mathrm{C}(\mathrm{dia} /\right.$ noite $\left.)\right]$, sobre a altura de plantas aos 40 dias após a semeadura.

\begin{tabular}{|c|c|c|c|c|c|}
\hline \multirow{3}{*}{$\begin{array}{l}\text { Peneiras } \\
\text { de crivo } \\
\text { oblongo }\end{array}$} & \multicolumn{4}{|c|}{ Doses de s-metolachlor (kg/ha) } & \multirow{3}{*}{$\begin{array}{l}\text { Equações de } \\
\text { regressão }\end{array}$} \\
\hline & 0 & 0,96 & 2,88 & 4,80 & \\
\hline & \multicolumn{4}{|c|}{ Altura de plantas $(\mathrm{cm})$} & \\
\hline 14 & $8,21 \mathrm{~b}$ & $6,17 \mathrm{c}$ & $6,08 \mathrm{c}$ & $5,79 \mathrm{c}$ & $\hat{Y}=6,5619$ \\
\hline 18 & 12,75 a & $12,17 \mathrm{~b}$ & $12,58 \mathrm{~b}$ & $9,71 \mathrm{~b}$ & $\hat{Y}=12,9863-0,548332 * * D\left(R^{2}=0,68\right)$ \\
\hline 21 & $13,83 \mathrm{a}$ & $14,25 \mathrm{a}$ & $16,17 \mathrm{a}$ & $15,04 \mathrm{a}$ & $\hat{Y}=14,8225$ \\
\hline
\end{tabular}

Médias seguidas por uma mesma letra, na coluna, não diferem entre si a 5\% de probabilidade pelo teste de Tukey.

**Significativo a $1 \%$ de probabilidade pelo teste $\mathrm{t}$. 
e) Biomassa seca da parte aérea

No tratamento sem herbicida houve maior acúmulo de biomassa seca na parte aérea de plantas de feijão quando estas se originaram de sementes maiores (Tabela 6). Estes resultados foram semelhantes aos encontrados por Nachi \& Le Guen (1996), os quais observaram correlação positiva entre o tamanho das sementes de genótipos de Vicia faba e o acúmulo de biomassa seca pelas plantas. Também Marcos Filho et al. (1986) verificaram que sementes menores de girassol originavam plântulas menores em relação àquelas originadas das sementes retidas nas peneiras maiores. Na dose comercial do s-metolachlor aplicada $(0,96 \mathrm{~kg} / \mathrm{ha})$ verificamse diferenças $(\mathrm{P}>0,05)$ para todos os tamanhos de sementes, onde, quanto menor a semente menor o acúmulo de biomassa seca. Cargill \& Santelmann (1971) observaram que trifluralin reduziu drasticamente o acúmulo de biomassa seca da parte aérea de plântulas de amendoim provenientes de sementes "pequenas"; entretanto, as plântulas originárias de sementes maiores não diferiram das plântulas testemunhas (sem herbicida).

$\mathrm{O}$ incremento das doses de s-metolachlor diminuiu o acúmulo de biomassa seca das plantas de feijão provenientes de todos os tamanhos das sementes (Figura 3). Analisandose as observações referentes ao acúmulo de biomassa seca na peneira 14, observa-se a ocorrência de brusca redução (quase pela metade), quando se compara as doses 0,00 e $0,96 \mathrm{~kg} / \mathrm{ha}$. Com o aumento do tamanho da semente esta amplitude foi diminuindo, a tal ponto que na peneira 21 não houve redução (Tabela 6). Estes resultados estão de acordo com Silva et al. (1981), os quais observaram inibição de 50\% do crescimento $\left(\mathrm{I}_{50}\right)$ das plantas de soja com a aplicação correspondente a 600,1050 e $1150 \mathrm{~g} /$ ha de metribuzin, para as plantas oriundas das sementes retidas nas peneiras 10, 13 e 15, respectivamente. Estes autores argumentam que sementes dos tamanhos 13 e 15 podem dar origem a plantas com maior reserva para metabolização do produto. Também, como des-

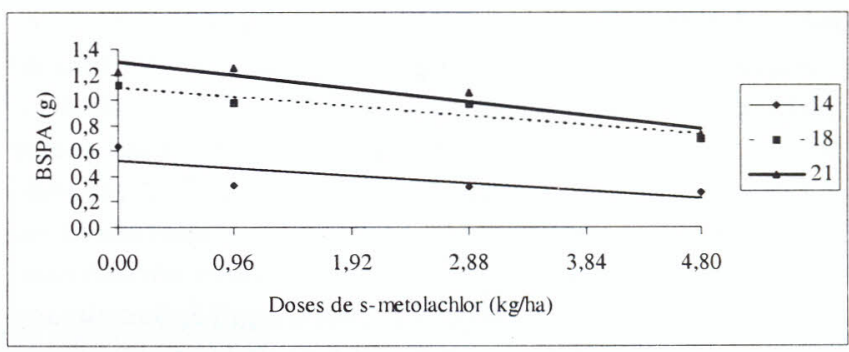

Figura 3. Efeito das doses de s-metolachlor (kg/ha) sobre a biomassa seca da parte aérea (BSPA) de plantas de feijão (cv. Pérola), provenientes de sementes de diferentes tamanhos (peneiras 14, 18 e 21), aos 40 dias após a semeadura.

crito para o efeito encontrado em relação à altura de plantas, o maior teor de reservas nutritivas nas sementes maiores pode ser o principal atenuador dos danos causados pelo smetolachlor.

De acordo com Andersen (1970), outra possível explicação para o fato das sementes grandes serem mais tolerantes a herbicidas, é que durante a condução dos experimentos, os herbicidas vão gradualmente se dissipando, e os cultivares de sementes maiores podem se manter pelas reservas nos cotilédones (dicotiledôneas), até a concentração do herbicida atingir níveis não letais. Também, segundo este autor, plântulas maiores produzidas por sementes maiores podem ter menor superfície relativa de absorção em relação ao volume total da plântula em relação às oriundas de sementes menores. Este fato pode ocasionar maior diluição dos herbicidas em plântulas provenientes de sementes maiores.

\section{f) Biomassa seca das raízes}

De maneira semelhante ao observado para a parte aérea das plantas, o acúmulo de biomassa seca das raízes das

Tabela 6. Efeito de doses de s-metolachlor ( $\mathrm{kg} / \mathrm{ha})$ e tamanhos de sementes de feijão (cv. Pérola), submetidas à baixa temperatura entre a semeadura e a emergência $\left[16 / 13 \pm 3^{\circ} \mathrm{C}(\right.$ dia/noite $\left.)\right]$, sobre a biomassa seca da parte aérea de plantas aos 40 dias após a semeadura.

\begin{tabular}{|c|c|c|c|c|c|}
\hline \multirow{3}{*}{$\begin{array}{c}\text { Peneiras } \\
\text { de crivo } \\
\text { oblongo }\end{array}$} & \multicolumn{4}{|c|}{ Doses de s-metolachlor (kg/ha) } & \multirow{3}{*}{$\begin{array}{l}\text { Equações de } \\
\text { regressão }\end{array}$} \\
\hline & 0 & 0,96 & 2,88 & 4,80 & \\
\hline & \multicolumn{4}{|c|}{ Biomassa seca da parte aérea de plantas (g) } & \\
\hline 14 & $0,6362 b$ & $0,3315 \mathrm{c}$ & $0,3137 \mathrm{~b}$ & $0,2710 b$ & $\begin{array}{c}\hat{Y}=0,520131-0,0611141 * * D \\
\left(R^{2}=0,60\right)\end{array}$ \\
\hline 18 & $1,1187 \mathrm{a}$ & $0,9735 \mathrm{~b}$ & 0,9675 a & $0,6977 \mathrm{a}$ & $\begin{array}{c}\hat{Y}=1,10559-0,0769509^{* *} \mathrm{D} \\
\left(\mathrm{R}^{2}=0,87\right)\end{array}$ \\
\hline 21 & $1,2178 \mathrm{a}$ & $1,2508 \mathrm{a}$ & $1,0547 \mathrm{a}$ & $0,7237 \mathrm{a}$ & $\begin{array}{c}\hat{Y}=1,29392-0,107486 * * D \\
\left(R^{2}=0,90\right)\end{array}$ \\
\hline
\end{tabular}

Médias seguidas por uma mesma letra, na coluna, não diferem entre si a $5 \%$ de probabilidade pelo teste de Tukey. **Significativo a $1 \%$ de probabilidade pelo teste t. 
plantas de feijão aumentou com o uso de sementes maiores, porém, não diferindo entre as peneiras 18 e 21 (Tabela 7). Kalavathi e Vanangamudi (1990) verificaram maior comprimento de raízes e da parte aérea, e maior produção de biomassa seca em plântulas de Cyamopsis tetragonoloba oriundas de sementes maiores. Burris et al. (1971), Edwards Junior \& Hartwig (1971) e Burris et al. (1973) descrevem que sementes "pequenas" e "médias" dão origem a plântulas com menor sistema radicular que sementes "grandes". Oliveira \& Sader (1984) encontraram correlação positiva entre o peso de 100 sementes de vários cultivares de Vigna ungiculata e a biomassa seca produzida por planta. Entretanto, segundo os mesmo autores, outros fatores, tais como a habilidade para translocar ou utilizar as reservas, podem exercer influência no tamanho e peso das plântulas.

A aplicação do s-metolachlor afetou o acúmulo de biomassa seca das raízes das plantas de feijão oriundas de todos os tamanhos de sementes (Figura 4). Também, como ocorrido para a parte aérea, a redução no acúmulo de biomassa seca das raízes para plantas oriundas das duas maiores sementes (18 a 21), só foi agravada com a utilização da maior dose do metolachlor (cinco vezes a dose média recomendada). Resultados semelhantes foram observados por Cargill \& Santelmann (1971), que, trabalhando com trifluralin, obsevaram que a dose de $0,56 \mathrm{~kg} /$ ha reduziu o comprimento das raízes de amendoim provindas de sementes "pequenas"; entretanto, foi necessário o dobro da dose deste herbicida para causar o mesmo efeito nas outras classes de sementes.

O tamanho da semente de feijão do cultivar Pérola submetido à baixas temperaturas no período entre a semeadura e a emergência das plântulas, influencia no crescimento das plantas e no nível de toxicidade do s-metolachlor a esta cultura. Portanto, o uso de sementes "grandes" (peneira 21) de feijão em áreas onde será aplicado o s-metolachlor, principalmente, no plantio de inverno, pode resultar em aumento dos níveis de injúria à cultura, se agravando com o aumento

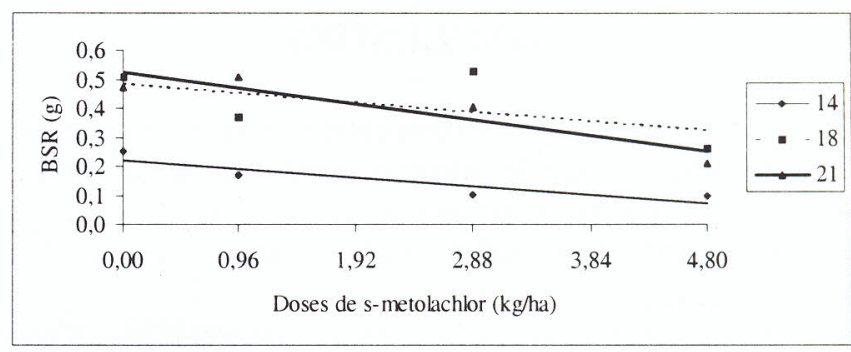

Figura 4. Efeito das doses de s-metolachlor ( $\mathrm{kg} / \mathrm{ha}$ ) sobre biomassa seca das raízes (BSR) de plantas de feijão (cv. Pérola), provenientes de sementes de diferentes tamanhos (peneiras 14, 18 e 21), aos 40 dias após a semeadura.

da dose deste produto, podendo resultar num aspecto visual inicial da cultura de difícil aceitação por parte dos produtores. Por outro lado, a aplicação deste herbicida nas doses próximas à comercial $(0,96 \mathrm{~kg} / \mathrm{ha})$ acentua a redução no acúmulo de matéria seca em plantas de feijão oriundas de sementes "pequenas". Também, observa-se que essa diminuição é um pouco mais pronunciada na parte aérea do que nas raízes das plantas. Experimentos de campo, em condições de baixa temperatura, poderão elucidar o que será mais prejudicial à produção da cultura, se a toxicidade visual inicial (sementes maiores) ou o menor acúmulo inicial de matéria seca (sementes menores), e, conseqüentemente, ajudar na decisão da melhor semente a ser utilizada. Não se pode afirmar que todos os cultivares que apresentam sementes "grandes" são mais propensos a apresentarem toxicidade visual pelo smetolachlor, pois fatores genéticos relacionados a absorção, a translocação e a detoxificação, podem ser diferentes. Todavia, cultivares que possuem sementes de maior tamanho e lentidão na emergência em condições de baixas temperaturas, apresentam maior probabilidade de serem mais suscetíveis ao s-metolachlor no plantio de inverno.

Tabela 7. Efeito de doses de s-metolachlor ( $\mathrm{kg} / \mathrm{ha}$ ) e tamanhos de sementes de feijão (cv. Pérola), submetidas à baixa tempe ratura entre a semeadura e a emergência $\left[16 / 13 \pm 3^{\circ} \mathrm{C}(\mathrm{dia} /\right.$ noite $\left.)\right]$, sobre a biomassa seca das raízes de plantas aos 40 dias após a semeadura.

\begin{tabular}{|c|c|c|c|c|c|}
\hline \multirow{3}{*}{$\begin{array}{l}\text { Peneiras } \\
\text { de crivo } \\
\text { oblongo }\end{array}$} & \multicolumn{4}{|c|}{ Doses de s-metolachlor (kg/ha) } & \multirow{3}{*}{$\begin{array}{l}\text { Equações de } \\
\text { regressão }\end{array}$} \\
\hline & 0 & 0,96 & 2,88 & 4,80 & \\
\hline & \multicolumn{4}{|c|}{ Biomassa seca das raízes de plantas (g) } & \\
\hline 14 & $0,2503 \mathrm{~b}$ & $0,1715 b$ & $0,1010 \mathrm{~b}$ & $0,0960 \mathrm{a}$ & $\begin{array}{c}\hat{Y}=0,221453-0,0309101 * D \\
\left(R^{2}=0,83\right)\end{array}$ \\
\hline 18 & $0,5055 \mathrm{a}$ & $0,3677 \mathrm{a}$ & $0,5282 \mathrm{a}$ & $0,2630 \mathrm{a}$ & $\begin{array}{c}\hat{Y}=0,488983-0,0337306 * D \\
\left(R^{2}=0,33\right)\end{array}$ \\
\hline 21 & $0,4703 \mathrm{a}$ & $0,5080 \mathrm{a}$ & 0,4052 a & $0,2125 \mathrm{a}$ & $\begin{array}{c}\hat{Y}=0,521758-0,0568326 * D \\
\left(R^{2}=0,85\right)\end{array}$ \\
\hline
\end{tabular}

Médias seguidas por uma mesma letra, na coluna, não diferem entre si a 5\% de probabilidade pelo teste de Tukey. *Significativo a $5 \%$ de probablidade pelo teste $\mathrm{t}$. 
Sérgio de Oliveira Procópio et al.

\section{CONCLUSÕES}

- Observou-se relação inversa entre o tamanho das sementes e a velocidade de emergência das plântulas de feijão;

- O tamanho das sementes de feijão e as doses do smetolachlor não interferiram no número de plantas emergidas;

- O s-metolachlor apresentou maior toxicidade visual nas plantas de feijão provenientes de sementes maiores;

- A aplicação do s-metolachlor reduziu a biomassa seca tanto da parte aérea como das raízes de plantas de feijão. Todavia, na dose próxima à comercial $(0,96 \mathrm{~kg} / \mathrm{ha})$ a maior redução na biomassa seca foi verificada quando as plantas foram oriundas de sementes de feijão menores (peneira 14).

\section{LITERATURA CITADA}

AGUIAR, I.B.; CARVALHO, N.M.; MAIMONI-RODELA, R.C.S.; DAMASCENO, M.C.M. Influência do tamanho sobre a germinação e o vigor de sementes de eucalipto. Revista Brasileira de Sementes, v.1, p.5358, 1979.

AMARAL, A.S.; SANTOS, E.C. Efeitos de herbicidas na emergência de plântulas de arroz. Revista Brasileira de Sementes, v.5, p.37-45, 1983.

ANDERSEN, R.N. Influence of soybean seed size on response to atrazine. Weed Science, v.18, p.162-164, 1970.

BEVERIDGE, J.L.; WILSIE, C.P. Influence of depth at planting; seed size, and variety on emergence and seedling vigor in alfafa. Agronony Journal, v.51, p.731-734, 1959.

BOLDT, L.D.; BARRETT, M. Factors in alachlor and metolachlor injury to corn (Zea mays) seedlings. Weed Technology, v.3, p.303-306, 1989.

BURRIS, J.S.; WAHAB, A.H.; EDJE, O.T. Effects of seed on seedling performance in soybeans. I. Seedling growth and respiration in the dark. Crop Science, v.11, p.492496, 1971.

BURRIS, J.S.; EDJE, O.T.; WAHAB, A.H. Effects of seed on seedling performance in soybeans. II. Seedling growth and respiration in the dark. Crop Science, v.13, p.207210, 1973.

CARGILL, R.L.; SANTELMANN, P.W. Influence of peanut seed and quality and variety on susceptibility to herbicides. Agronomy Journal, v.63, p.98-100, 1971.
CAZETTA, J.O.; SADER, R.; IKEDA, M. Efeito do tamanho no desempenho germinativo de sementes de feijoeiro (Phaseolus vulgaris L.). Científica Jaboticabal, v.23, p.65-71, 1995.

COLVIN, D. L.; STALL, W.M. Weeds in the Sunshine: Diagnosing herbicide injury-1998. http://edis.ifas.ufl.edu/ scripits/htmlgem.exe?body\&DOCUMENT_WG053.

COSTA, A.V.; FONTES, L.A.N.; SEDIYAMA, T.; GALVÃO, J.D. Efeito da profundidade de plantio e do tamanho da semente na emergência e algumas características agronômicas da soja [Glycine max (L.) Merr.]. Experientiae, v.16, p.151-172, 1973.

COTTINGHAM, C.K.; HATZIOS, K.K. Basis of differential tolerance of two corn hybrids (Zea mays) to metolachlor. Weed Science, v.40, p.359-363, 1992.

EDWARDS JUNIOR, C.J.; HARTWIG, E.E. Effect of seed size upon rate of germination in soybeans. Agronomy Journal, v.63, p. 429-430, 1971.

FIGUEIREDO, M.S.; VIEIRA, C. Efeito do tamanho das sementes sobre o stand, produção e altura das plantas na cultura do feijão. Revista Ceres, v.17, p.47-60, 1970.

FUENTES, J.R.; SILVA, J.F.; VIEIRA, C.; CONDÉ, A.R. Tolerância de cultivares de feijão (Phaseolus vulgaris L.) aos herbicidas alachlor e linuron. Revista Ceres, v.31, p.136-145, 1984.

FUERST, E.P.; GRONWALD, J. W. Induction of rapid metabolism of metolachlor in sorghum shoots by CGA92194 and other antidotes. Weed Science, v.34, p.354$361,1986$.

GILLIOLI, J.L. Influência do tamanho das sementes sobre algumas características agronômicas da soja. In: SEMINÁRIO NACIONAL DE PESQUISA DE SOJA, 1. Londrina, 1978. Anais... Londrina, PR: EMBRAPA/ CNPS, 1979. p. 309-315.

HSU, K.H.; KIM, C.J.; WILSON, L.A. Factors affecting water uptake of soybean during soaking. Cereal Chemistry, v.60, p.208-211, 1983.

JOHNSON, D.R.; LUEDDERS, V.D. Effect of planted seed size on emergence and yield soybeans (Glycine max. (L.) Merr,). Agronomy Journal, v.66, p.117-118, 1974.

JORDAN, G.L.; HARVEY, R.G. Response of processing peas (Pisum sativum) and annual weeds to acetanilide herbicides. Weed Science, v.26, p.313-317, 1978. 
KALAVATHI, D.; VANANGAMUDI, K. Seed size, seedling vigour and storability in clusterbeans. Madras Agricultural Journal, v.77, p.39-40, 1990.

KLIMONT, K. The effect of herbicides on soybean seed quality. Biuletyn Instytutu Hodowli i Aklimatyzacji, n.198, p.127-132, 1996.

MARCOS FILHO, J.; KOMATSU, Y.H.; NOVEMBRE, A.D.I.C.; FRANTIN, P.; DEMETRIO, C.C.B. Tamanho de semente e desempenho do girassol: II. Vigor. Revista Brasileira de Sementes, v.8, p.21-31, 1986.

NACHI, N.; LE GUEN, J. Dry matter accumulation and seed yield in faba bean (Vicia Faba L.) genotypes. Agronomie, v.16, p.47-53, 1996.

OLIVEIRA, A.F.F.; SADER, R. Capacidade germinativa e vigor de cultivares de caupi. Revista Brasileira de Sementes, v.6, p.21-29, 1984.

PEREIRA, F.A.R.; BAZONI, R. Avaliação de herbicidas na cultura da soja em áreas de cerrado de Mato Grosso do Sul. Campo Grande, MS. EMPAER, 1995, 38 p. (EMPAER-MS. Documento 45).

PETER, C.J.; WEBER, J.B. Adsorption, mobility, and efficacy of alachlor and metolachlor as influenced by soil properties. Weed Science, v.33, p.874-881, 1985.

PUTNAM, A.R.; RICE JUNIOR, R.P. Environmental and edaphic influences on the selectivity of alachlor on snap beans (Phaseolus vulgaris). Weed Science, v.27, p.570$574,1979$.
ROWE, L.; ROSSMAN, E.; PENNER, D. Differential response of corn hybrids and inbreds to metolachlor. Weed Science, v.38, p.563-566, 1990.

SILVA J.F.; SILVA, J.F.; SILVA, R.F.; CONDÉ, A.R. Tolerância do tamanho da semente de soja [Glycine max (L.) Merr. ] ao metribuzin. Planta Daninha, v.4, p.9296, 1981.

SILVA, J.M. Relações entre classes de largura e qualidade fisiológica das sementes de soja [Glycine max (L.) Merrill]. Pelotas, 1979, 144p. Universidade Federal de Pelotas. (Dissertação de Mestrado).

SILVA, W.R.; MARCOS FILHO, J. Efeitos do peso e do tamanho das sementes de milho sobre a germinação e vigor em laboratório. Revista Brasileira de Sementes, v.1, p.39-52, 1979.

SINGH, J.N.; TRIPATHI, S.K.; NEGI, P.S. Note on the effect of seed size on germination, growth and yield of soybean [Glycine max. (L.) Merrill]. Indian Journal Agriculture Science, v.42, p.83-86, 1972.

VECHI, C. Physiological responses of cowpea [Vignasinensis (L.) Savi], seeds to differential deterioration level. 1970. 72p. Mississippi State University. (Dissertação de Mestrado).

VIGER, P.R.; EBERLEIN, C.V.; FUERST, E.P. Influence of available soil water content, temperature, and CGA154281 on metolachlor injury to corn. Weed Science, v.39, p.227-231, 1991. 
